\title{
Recurrent mass selection for upright plant architecture in common bean
}

\author{
Luiz Paulo Miranda Pires ${ }^{1 *}$, Magno Antonio Patto Ramalho1 ${ }^{1}$ Ângela de Fátima Barbosa Abreu², Monica Christina Ferreira ${ }^{3}$
}

${ }^{1}$ Federal University of Lavras - Dept. of Biology/Genetics and Plant Breeding, C.P. 3037 - 37200-000 - Lavras, MG - Brazil.

${ }^{2}$ Embrapa Rice and Beans - Rod. G0-462, km 12, C.P.

179 - Zona Rural - 75375-000 - Santo Antônio de Goiás, GO - Brazil.

3University of São Paulo/ESALQ - Dept. of Genetics, C.P. 09 - 13418-900 - Piracicaba, SP - Brazil.

*Corresponding author <lpmpires@posgrad.ufla.br>

Edited by: Leonardo Oliveira Medici

Received July 01, 2013

Accepted January 03, 2014
ABSTRACT: Plant with a more upright architecture offers many advantages to farmers. Recurrent mass selection (RS) programs for carioca type common bean have been implemented for the purpose of obtaining new lines that will generate the high yields that are associated with upright plant architecture. This study aimed to assess the efficiency of recurrent mass selection (RS) for upright plant architecture in common bean (Phaseolus vulgaris) and the effect of RS on grain yield and to verify whether or not there is still variability in the population that favors continuing selection programs, using information obtained from progenies evaluated in cycle five (CV) and cycle eight (CVIII) of the RS program. Mass selection for more upright plants was performed visually in the " $\mathrm{S}_{0}$ " generation before flowering. Progenies $\mathrm{S}_{0: 3}$ and $\mathrm{S}_{0: 4}$ were evaluated in 2009 (CV) and 2011 (CVIII). Heritability $\left(\mathrm{h}^{2}\right)$ and RS progress were estimated using adjusted means. After eight selection cycles, the population subjected to RS still had enough genetic variability to achieve continued success through recurrent selection. The RS progress was $1.62 \%$ per cycle for the growth habit scores and $6.81 \%$ for grain yield.

Keywords: plant Breeding, genetic progress, genetic variability

\section{Introduction}

The demand for new cultivars that combine greater grain yield within commercial standards is growing, especially in the case of the carioca type bean (Phaseolus vulgaris) (beige with brown stripes) and more upright plant architecture. Plant with a more upright architecture is good for farmers because this structure offers advantages such as: i) ease of crop management, especially in mechanical crop operations, allowing more freedom of movement of implements without damaging the plants, ii) reduction of losses at harvest, with better quality grain. If the harvest occurs during periods of prolonged rains, it is possible to delay it with less grain damage; iii) lower incidence of disease as upright plants facilitate air circulation, thereby providing less favorable conditions for certain pathogens.

For breeders to obtain lines that combine upright plants with high commercial grain yield the greatest difficulty is the large number of genes involved in the controling of these traits and the effect on the environment when these traits find expression (Kelly and Adams, 1987). For this reason, the probability of obtaining success in any one single selection cycle is low. The principal alternative available is the use of recurrent selection (Hallauer et al., 2010).

One of the restrictions of the use of recurrent selection is the delay in obtaining each selection cycle when assessing and recombining progenies. An alternative is mass selection, which is recommended for traits that present high heritability. The use of recurrent mass selection in autogamous plants is not very frequent. In the case of investigating recurrent selection with a view to obtaining more upright plants and the possible effect of this selection on grain yield, no report has been found in the literature.
Recurrent selection programs for carioca type common bean has been conducted for the purpose of obtaining new lines with the high yields that are associated with upright plant architecture (Menezes Júnior et al., 2008). In cycle five (CV), progenies were obtained which were assessed for certain generations; the same procedure was adopted in cycle eight (CVIII). Based on this, the present study was carried out with the aim of assessing the efficiency of RS for upright growth habit and the effect of this selection on grain yield in common bean, and to check if there is still variability in the population after eight cycles of RS.

\section{Materials and Methods}

The RS program began in 2001. The base population was obtained from a dialelic cross drawing on ten inbred lines with upright plants without the reciprocal (Table 1). The details of how recurrent selection was conducted up to the third cycle (CIII) were presented by Menezes Junnior et al. (2008). From this cycle on, the selection process came to be mass selection; in other words, the $\mathrm{S}_{0}$ population was recombined by means of intercrossing the plants that proved to be more upright. The " $\mathrm{F}_{2}$ " seeds collected were multiplied and collected in bulk to generate the new $\mathrm{S}_{0}$ population and proceed with the process. Common bean in the region may be sown in three seasons, and one recurrent selection cycle involves two crop seasons. So, three cycles are conducted over a two year period. CV was obtained in 2009 and, after recombination, progenies were taken for assessing other traits. The same occurred in CVIII obtained in 2011. The focus of this study is the assessment of progenies of $\mathrm{CV}$ and CVIII.

The experiments in the assessment of the progenies were conducted in Lavras, in the state of

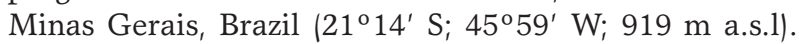


The CV and CVIII progenies were assessed starting with the $\mathrm{S}_{0: 2}$ generation. $\mathrm{S}_{0: 2}$ progenies of $\mathrm{CV}$ were assessed in experiments that had been sown in February 2009, whereas the $S_{0: 2}$ progenies of CVIII were assessed from July 2011onward. The details of the experiments are shown in Table 2.

In all experiments two controls were always included - the BRSMG Majestoso cultivar, hereinafter called simply 'Majestoso', chosen as a yield standard for the carioca type cultivars (Abreu et al., 2007) and 'BRS Supremo', a cultivar of black beans, chosen as a reference in terms of upright plant growth (Costa et al., 2009).

The experiments were continuously managed in a way commensurate with that recommended for the crop in the region, except that no phytosanitary treatment was applied. The traits assessed were plant growth habit, with visual assessment undertaken by means of a scoring scale ranging from 1 (prostrate plant) to 9 (upright plant), and grain yield.

The data in reference to the traits assessed were subjected to analysis of variance (ANOVA) per generation that treated all the effects of the model as random, except for the mean value. According to the expected mean squares of ANOVA, heritability $\left(\mathrm{h}^{2}\right)$ of the progenies assessed was estimated using the following equation:

$h^{2}=\frac{Q_{1}-Q_{2}}{Q_{1}}$

in which: $Q_{1}$ : mean square among progenies of analyses of variance; $Q_{2}$ : Mean square error. The confidence interval of $\mathrm{h}^{2}$ was obtained using the expressions presented by Knapp et al. (1985), with $\alpha=0.05$.

With the 47 progenies of the $S_{0: 3}$ and $S_{0: 4}$ generations of $\mathrm{CV}$ and equal number of $\mathrm{S}_{0: 3}$ and $\mathrm{S}_{0: 4}$ progenies of CVIII, combined analysis of variance was carried out, with the two controls in common to the two selection cycles serving as a reference (Pimentel-Gomes, 2009). Using the adjusted mean values, genetic progress (GP) per cycle from selection was estimated by the following estimator:

G.P. $=\left[\frac{\left(\frac{\text { mean of the progenies ofCVIII - mean of the progenies of } C V}{3}\right)}{\text { mean of the progenies of } C V}\right]$

\section{Results}

Analyses of variance (data not shown) showed differences among the progenies $(p \leq 0.01)$. Among traits in both selection cycles, it was observed in combined analysis of variance that there were differences $(p \leq$ 0.01) between cycles in both traits (Table 3).

The mean values obtained varied among the generations in the same cycle and among the cycles themselves. As the mean genotypic effect of the progenies over the generations of endogamy derives only from the contribution of the loci in heterozygosis (d), and this is normally not very expressive for the common bean crop, it may be inferred that the changes in the mean value of the generations must in large part be due to the environmental conditions prevailing in the different periods of assessment.

The estimates of heritability for selection in the mean value of the progenies showed the existence of variation among them (Table 4). The performance of the progenies in CVIII was greater than that of CV. The estimate of genetic progress obtained for growth habit scores was $4.86 \%$, which corresponds to $1.62 \%$ per cycle. The same estimate for grain yield was much greater, $6.81 \%$ (Table 5).

Table 1 - Relation of parents used in recurrent selection program to plant upright dry bean.

\begin{tabular}{|c|c|c|c|}
\hline Lines & Origin & Type of grain & Plant architecture \\
\hline Carioca MG & UFLA & Beige with brown stripes & Upright \\
\hline CNFC 9454 & Embrapa & Beige with brown stripes & Upright \\
\hline CNFC 9455 & Embrapa & Beige with brown stripes & Upright \\
\hline CNFC 9458 & Embrapa & Beige with brown stripes & Upright \\
\hline CNFC 9466 & Embrapa & Beige with brown stripes & Upright \\
\hline CNFC 9471 & Embrapa & Beige with brown stripes & Upright \\
\hline CNFC 9484 & Embrapa & Beige with brown stripes & Upright \\
\hline IAPAR 81 & IAPAR & Beige with brown stripes & Upright \\
\hline LP 9876 & IAPAR & Beige with brown stripes & Upright \\
\hline IPR Uirapuru & IAPAR & Black & Upright \\
\hline
\end{tabular}

Table 2 - Details of experiments designed to assess upright plant architecture of $\mathrm{CV}$ and CVIII progenies of the recurrent selection program.

\begin{tabular}{llcc}
\hline & & \multicolumn{2}{c}{ Generations } \\
\cline { 3 - 4 } & & $\mathrm{S}_{0: 3}$ & $\mathrm{~S}_{0: 4}$ \\
\hline \multirow{4}{*}{ CV } & No. of progenies & 47 & 47 \\
& No. of replications & 3 & 3 \\
& Experimental design & Lattice $7 \times 7$ & Lattice $7 \times 7$ \\
& Month/Year & July/2009 & Nov/2009 \\
\hline \multirow{4}{*}{ CVIII } & No. of progenies & 98 & 47 \\
& No. of replications & 3 & 3 \\
& Experimental design & Lattice & Lattice $7 \times 7$ \\
& Month/Year & $10 \times 10$ & Nov/2011 \\
\hline
\end{tabular}

Table 3 - Combined analysis of variance using the adjusted average of the progenies for plant architecture and grain yield in $\mathrm{kg} \mathrm{ha}^{-1}$.

\begin{tabular}{|c|c|c|c|c|c|}
\hline \multirow{2}{*}{$\begin{array}{l}\text { Variation } \\
\text { source }\end{array}$} & \multirow{2}{*}{$\begin{array}{c}\text { Freedom } \\
\text { degree }\end{array}$} & \multicolumn{2}{|c|}{ Grain yield } & \multicolumn{2}{|c|}{ Plant architecture ${ }^{1}$} \\
\hline & & $\begin{array}{l}\text { Mean } \\
\text { square }\end{array}$ & $\mathrm{F}$ & $\begin{array}{l}\text { Mean } \\
\text { square }\end{array}$ & $\mathrm{F}$ \\
\hline Prog & 93 & 212353.9 & $2.39^{* *}$ & 0.83 & 1.26 \\
\hline Prog CV & 46 & 166262.58 & $1.87^{* *}$ & 0.60 & 0.91 \\
\hline Prog CVIII & 46 & 93551.99 & 1.05 & 0.99 & 1.50 \\
\hline CV vs CVIII & 1 & 7797445.7 & $87.85^{\text {* * }}$ & 3.96 & $5.99^{*}$ \\
\hline Error & 93 & 88755 & & 0.66 & \\
\hline
\end{tabular}

*, ${ }^{* *}$ significant at $5 \%$ and at $1 \%$ by the $\mathrm{F}$ test; ${ }^{\text {PPlant architecture score in }}$ which 1 refers to totally prostrate plants and 9 to completely upright plants. 
Table 4 - Heritability estimates for selection of the mean of the progenies of the grain yield ( $\mathrm{kg} \mathrm{ha}^{-1}$ ) and plant architecture score obtained in generations $\mathrm{S}_{0: 3}$ and $\mathrm{S}_{0: 4}$ of $\mathrm{CV}$ and CVIII of recurrent selection in Lavras, MG.

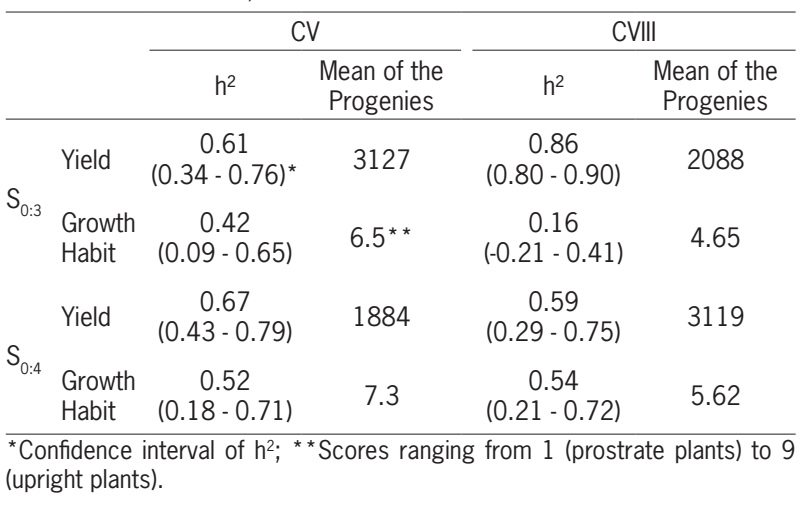

Table 5 - Estimates of genetic progress per cycle, obtained from recurrent selection for upright plant architecture and high grain yield.

\begin{tabular}{lcc}
\hline & $\begin{array}{c}\text { Plant architecture } \\
\text { (scores 1 to 9) }\end{array}$ & $\begin{array}{c}\text { Grain yield } \\
\left(\mathrm{kg} \mathrm{ha}^{-1}\right)\end{array}$ \\
\hline Mean value of CV progenies (MCV) & 5.950 & 1991 \\
Mean value of CVIII progenies (MCVIII) & 6.240 & 2399 \\
Overall Mean & 6.100 & 2195 \\
Total Progress $\left[\frac{\text { MCVIII }- \text { MCV }}{M C V}\right]$ & 0.048 & 0.204 \\
Progress per cycle (\%) $\left[\frac{\text { Total Progress }}{3}{ }^{*} 100\right]$ & 1.620 & 6.810 \\
Averages of the CV controls & 6.280 & 1788 \\
Averages of the CVIII controls & 4.310 & 2686 \\
\hline
\end{tabular}

\section{Discussion}

Overlapping occurred in the confidence interval of heritability, showing that the estimates obtained in both selective cycles are similar (Table 4). It may be deduced that there is still genetic variability that can continue obtaining success from selection. These results corroborate the ones obtained by Silva et al. (2010), who estimated the genetics' progress after eight cycles of the recurrent selection with the aim of obtaining lines with high yield. These authors verified that this selection did not reduce the genetic variability for this feature from estimates of $h^{2}$ of the progenies evaluated in different selection cycles.

Recurrent selection is a cyclical breeding process in which an increase is expected in the mean value of the population, without expressive reduction in genetic variability over the cycles (Hallauer et al., 2010). It was possible to observe a trend towards an increase in the mean value of the progenies over the recurrent selection cycles. The mean values of plant architecture scores and grain yield are greater in CVIII than in CV. The estimate of genetic progress from selection was $1.62 \%$ per cycle for plant architecture and $6.81 \%$ per cycle for grain yield (Table 5).
As recurrent mass selection was carried out for plant architecture only, it is difficult to explain why grain yield showed such expressive genetic progress, moreso because there are reports in the literature that there is negative genetic correlation between plant architecture scores and grain yield (Collicchio et al., 1997). However, Silva et al. (2009) commented that although these correlation estimates are negative, they exhibit small magnitude, making it possible to simultaneously select more productive progenies with better plant architecture, associated with the large number of progenies assessed. An explanation for the high estimate of genetic progress for grain yield was the experimental precision obtained in the experiments for progeny assessments of CVIII, which allowed better discrimination of the superior progenies to be selected. Another explanation is that there were only recombined vigorous plants, which probably contributed to increases in the grain yield. In addition, the RS progress for the trait reflects the best success seen in prior evaluations to $S_{0: 3}$, which originated the progenies of the CVIII related to CV.

The size of the bean has also been a trait that is closely related to plant architecture because it is difficult to associate, in one line, both upright plant architecture and a commercial size bean. Most upright plant architecture cultivars have small beans, a fact that has impeded market acceptance. Nevertheless, the flower buds used in carrying out crosses were those that flowered first and which were visually more developed, and this may have contributed to increasing the size of the beans and consequently the yield. These results corroborate those obtained by Cunha et al. (2005), who linked positive gains with the selection from the evaluation of plant bean progenies to productivity, type of grains and plant architecture, simultaneously, indicating at first that the correlation between plant architecture and productivity can generate genetic gain with the selection.

In CVIII, progenies with an average score for plant architecture greater than that of the 'BRS Supremo' cultivar were obtained, which is the standard with regard to upright plant architecture currently available on the market (Costa et al., 2009), as well as progenies with a performance greater than the control 'Majestoso', known for its high grain yield (Abreu et al., 2007).

\section{Conclusions}

Genetic progress from recurrent selection was $1.62 \%$ per cycle for the plant architecture trait and 6.81 $\%$ per cycle for grain yield. After eight selection cycles, the population that was subjected to recurrent selection still had enough genetic variability to favor continued success from recurrent selection.

\section{Acknowledgements}

To Coordination for the Improvement of Higher Level Personnel (CAPES), and the Brazilian National 
Council for Scientific and Technological Development (CNPq) for granting the scholarship; to Minas Gerais State Foundation for Research Support (FAPEMIG) financial support for the realization of the research Project.

\section{References}

Abreu, A.F.B.; Ramalho, M.A.P.; Carneiro, J.E.S.; Peloso, M.J.D.; Paula Júnior, T.J.; Faria, L.C.; Melo, L.C.; Barros, E.G.; Moreira, M.A.; Pereira Filho, I.A.; Martins, M.; Santos, J.B.; Costa, J.G.C.C.; Sartorato, J. 2007. BRSMG Majestoso: another common bean cultivar of carioca grain type for the state of Minas Gerais. Crop Breeding and Applied Biotechnology 7: 403-405.

Collicchio, E.; Ramalho, M.A.P.; Abreu, A.F.B. 1997. Association between plant architecture common bean and grain size. Pesquisa Agropecuária Brasileira 32: 297-304 (in Portuguese, with abstract in English).

Costa, J.G.C.; Faria, L.C.; Rava, C.A.; Peloso, M.J.; Melo, L.C.; Díaz, J.L.C.; Faria, J.C.; Silva, H.T.; Sartorato, A.; Bassinello, P.Z.; Zimmermann, F.J.P. 2009. BRS Supremo: cultivar of common bean grain black and upright plant architecture nominated for the south and midwest = BRS Supremo: cultivar de grão preto de feijoeiro comum de porte ereto indicada para as regiões Sul e Centro-Oeste. Santo Antônio de Goiás, GO, Brazil. (Comunicado Técnico, 87) (in Portuguese).

Cunha, W.G.; Ramalho, M.A.P.; Abreu, A.F.B. 2005. Selection aiming at upright growth habit common bean with carioca type grains. Crop Breeding and Applied Biotechnology 5: 379-386.
Hallauer, A.R.; Carena, M.J.; Miranda Filho, J.B. 2010. Quantitative Genetics in Maize Breeding. Iowa State University Press, Ames, IA, USA.

Kelly, J.D.; Adams, M.W. 1987. Phenotypic recurrent selection in ideotype breeding of plant beans. Euphytica 36: 69-80.

Knapp, S.J.; Stroup, W.W.; Ross, W.M. 1985. Exact confidence intervals for heritability on a progeny mean basis. Crop Science 25: 192-194.

Menezes Júnior, J.A.N.; Ramalho, M.A.P.; Abreu, A.F.B. 2008. Recurrent selection for three characters of common bean. Bragantia 67: 833-838 (in Portuguese, with abstract in English).

Pimentel-Gomes, F. 2009. Combined analysis of the experiments in randomized blocks

with common treatments. p. 313-328. In: Course of experimental statistics $=$ Curso de estatística experimental. 15ed. FEALQ, Piracicaba, SP, Brazil (in Portuguese).

Ramalho, M.A.P.; Abreu, A.F.B.; Santos, J.B.; Nunes, J.A.R. 2012. Applications of quantitative genetics in plant breeding autogamous $=$ Aplicações da genética quantitativa no melhoramento de plantas autógamas. Lavras, MG, Brazil (in Portuguese).

Silva, C.B.; Abreu, A.F.B.; Ramalho, M.A.P. 2009. Association between plant architecture and grain yield in progenies common bean with upright and prostrate. Pesquisa Agropecuária Brasileira 44: 1647-1652 (in Portuguese, with abstract in English).

Silva, G.S.; Ramalho, M.A.P.; Abreu, A.F.B.; Nunes, J.A.R. 2010. Estimation of genetic progress after eight cycles of recurrent selection for common bean grain yield. Crop Breeding and Applied Biotechnology 10: 351-356. 